E3S Web of Conferences 1, 11003 (2013)

DOI: $10.1051 / \mathrm{e} 3$ sconf/20130111003

(c) Owned by the authors, published by EDP Sciences, 2013

\title{
Comparative Study of the Accumulation of Ni in Different Tissues of Mussels and Soft Clams
}

\author{
O. Chalkiadakis ${ }^{1,2}$, V. Paraskevopoulou ${ }^{2}$, I. Roussos $^{1}$, M. Dassenakis ${ }^{2}$ and N. Lydakis Simantiris ${ }^{1}$ \\ ${ }^{1}$ Laboratory of Environmental Chemistry and of Biochemical Processes, Department of Natural Resources and the \\ Environment, Technological Education Institution of Crete, 3 Romanou, PO BOX 89, 73103 Chania, Crete, GREECE, \\ lydakis@chania.teicrete.gr \\ ${ }^{2}$ Laboratory of Environmental Chemistry, Faculty of Chemistry, National and Kapodistrian University of Athens, \\ Panepistimioupoli Zografou, 15771, Athens, GREECE, edasenak@chem.uoa.gr, ochalkiadaki@chem.uoa.gr, \\ vparask@chem.uoa.gr
}

\begin{abstract}
Two bivalves, the mussel Mytilus galloprovincialis, and the soft clam Callista chione were exposed to various Ni concentrations for a total period of 20 days, and then a depuration period of 10 days followed. Nickel accumulation in gills, mantle and the remaining body of the animals was measured after 5, 10, 15 and 20 days of exposure to Ni-contaminated seawater. The two organisms showed different behavior regarding Ni accumulation in all three tissues examined. In all concentrations, $\mathrm{Ni}$ accumulation increased with time in all three tissues of Mytilus galloprovincialis with gills being the most effective accumulator per dry mass. On the other hand, Callista chione showed an initial response to Ni contamination the first 5 days, followed by stabilization or even a slight decrease of $\mathrm{Ni}$ accumulation.
\end{abstract}

Key words: Nickel acuumulation, Mytilus galloprovincialis, Callicta chione

\section{Introduction}

Heavy metals are natural constituents of the Earth's crust. They are stable and cannot be degraded or destroyed, therefore they tend to accumulate in soils and sediments. However, human activities have drastically altered the biochemical and geochemical cycles and balance of some heavy metals. Some of them, such as copper, nickel, chromium and iron, are essential in very low concentrations for the survival of all forms of life. These are described as essential trace elements. Only when they are present in greater quantities, can these, like the heavy metals lead, cadmium and mercury which are already toxic in very low concentrations, cause metabolic anomalies.

Heavy metals are dangerous because they tend to bioaccumulate. Bioaccumulation means an increase in the concentration of a chemical in a biological organism over time, compared to the chemical's concentration in the environment. Compounds are considered to accumulate in organisms when they are taken up and stored faster than they are metabolized or excreted. In general, heavy metals produce their toxicity by forming complexes or "ligands" with biological molecules. These modified biological molecules lose their ability to function properly, and result in malfunction or death of the affected cells.

Nickel is a naturally abundant transition metal which occurs extensively in the earth's crust and, as a consequence of natural and anthropogenic processes, it can be found, often in considerable concentrations, in the air, soil, sediments and water. As with all metals and chemicals, excessive amounts of nickel in any of these environmental compartments can result in deleterious impacts on the quality of the environment for flora and fauna.

For animals, nickel is an essential micronutrient with important biological role, since there are enzymes (i.e. urease, $\mathrm{NiFe}$ hydrogenases etc) which contain nickel in their active centres. In high concentrations, however, $\mathrm{Ni}$ is toxic. For example, nickel and certain nickel compounds have been listed by the National Toxicology Program (NTP) as being reasonably anticipated to be carcinogens. The International Agency for Research on Cancer (IARC) has listed nickel compounds within group 1 (there is sufficient evidence for carcinogenicity in humans) and nickel within group 2B (agents which are possibly carcinogenic to humans). Also, nickel is on the ACGIH Notice of Intended Changes as a Category A1, 
confirmed human carcinogen. (Nordberg et al, 2007, and references therein).

Mussels and clams are common in most of the Mediterranean coastal areas and often they sustain commercial fisheries in some areas of the Mediterranean basin. Among the most common mussels and clams are Mytilus galloprovincialis and Callista chione, respectively. In general, these organisms are considered sensitive to heavy metals contamination of their living environment, and also as accumulators of these pollutants. Despite the economic importance of Callista chione, not much experimental work has been published regarding the behavior of this animal in a heavy metal polluted environment. In this work, a comparison of the nickel accumulation in different tissues of Callista chione and Mytilus galloprovincialis (an already well-studied organism [Nesto et al., 2007; Zhou et. al., 2008]) is presented, towards an assessment of the potential utilization of these organisms as nickel contamination bioindicators. To achieve this goal, the two organisms were grown in laboratory conditions, in seawater contaminated with different concentrations of $\mathrm{Ni}$.

\section{Materials and Methods}

Mussels (Mytilus galloprovincialis) were collected from the marine farms located in Nea Peramos (Neraki) whereas soft clams (Callista chione) were hand collected by scuba divers from Elefsis Gulf. Both species were brought alive to the laboratory. Care was taken to use individuals of the same size, since size roughly represents the age of the organisms. There was no animal harvesting at spawning periods, since the organisms' nutrition (filtering rate) is different at that period. Seawater samples were collected from the same areas and analyzed for their $\mathrm{Ni}$ concentration, which repeatedly was found very low (data not shown).

After their arrival at the laboratory, a group of 10 animals was examined in order to measure the concentrations of accumulated $\mathrm{Ni}$ in their soft tissues (gills, mantle, and the remaining body) due to the presence of the heavy metal in seawater. The rest of the animals were kept in $70 \mathrm{~L}$ aquaria with natural, pumpaerated seawater of $36 \pm 1 \%$ salinity. After five days of adaptation to the laboratory conditions, the organisms were exposed to $0,5 \mathrm{ppm}, 1,0 \mathrm{ppm}, 2,5 \mathrm{ppm}$ and 20,0 ppm Ni for 20 days, by addition of appropriate volumes of $\mathrm{NiCl}_{2}, 1000 \mathrm{ppm}$ stock solution. Half of the water volume was replaced by fresh seawater every third day (with the appropriate addition of $\mathrm{NiCl}_{2}$ stock solution). 30 animals were removed every 5 days, after adaptation period, and separated to 3 replicates of 10 animals. The animals were dissected and the gills, mantle, and the remaining body were separated. After the 20 days period, the remaining animals were tranferred to fresh seawater for a 10 days depuration experiment. After depuration period, these animals were dissected as described above. Animals were also maintained in clean seawater (control samples) and treated the same way as Ni-exposed samples. Mortality was restricted only to mussels exposed to 20,0 ppm Ni (see results). Soft clams showed no mortality, even at the highest $\mathrm{Ni}$ concentration. After dissection, same tissues were pooled together and kept in $-24^{\circ} \mathrm{C}$ until use.

Tissue samples used for the determination of $\mathrm{Ni}$ were lyophilized (LabCongo, Freezone 4.5 lyophilizer) and homogenized to fine powder. $300-500 \mathrm{mg}$ of the dry tissues were digested with concentrated $\mathrm{HNO}_{3}$ in covered PTFE containers overnight and diluted with MilliQ water to $25 \mathrm{~mL}$ final volume. After acid digestion, the $\mathrm{Ni}$ content was determined by graphite furnace atomic absorption spectrometry (Varian SpecraAA-640Z GTA 100). For quality assurance and quality control, standards and blanks were also digested and measured. The results of all the measurements were converted to concentration in dry mass ( $\mu \mathrm{g}$ of $\mathrm{Ni} / \mathrm{g}$ of dry tissue). Values from the same sample with difference of more than $10 \%$ were rejected and the measurement was repeated.

\section{Results and Discussion}

Figures 1, 2, and 3 present data from the three different tissues under examination, namely the gills, mantle and the remaining body, removed from mussels and clams exposed to three different concentrations of nickel $(0.5$, 1.0 , and $2.5 \mathrm{ppm}$ ) for $5,10,15$, and 20 days. Data for the same tissues from animals which were transferred to clean seawater for 10 days are also presented. To make comparisons easier, we used the same y-axis scale for the same Ni concentrations. From the three sets of data it becomes readily obvious that the two bivalves under examination behave differently in the presence of nickel in their living environment. In all $\mathrm{Ni}$ concentrations in seawater, the tissues from mussels showed an increasing concentration with the days of exposure. Consistently, the mantle showed less amount of $\mathrm{Ni}$ accumulated in it per dry mass, whereas gills seem to accumulate more $\mathrm{Ni}$, at least after the tenth day of exposure. It seems that at relatively lower $\mathrm{Ni}$ concentrations in seawater $(0.5$ and $1.0 \mathrm{ppm}$ ) the body accumulates more nickel per dry mass as compared to gills, an effect which disappears at higher concentrations. After 10 days of depuration, the $\mathrm{Ni}$ content in the three tissues from mussels decreases, however the remaining nickel is considerably more than the background levels in all the examined tissues.

On the other hand, Callista chione exhibited a totally different behavior. As data in Figures 1, 2, and 3 show, this bivalve accumulated much less nickel when exposed to the same concentrations with mussels. A response to $\mathrm{Ni}$ contamination seems to take place the first days of exposure, which is reduced or disappeared with time. In general, more $\mathrm{Ni}$ was found in the remaining body of the soft clams per dry mass, compared to the gills and mantle, which showed similar behavior. Since no considerable amount of nickel was accumulated in soft clams, the depuration period did not affect much the $\mathrm{Ni}$ levels in the examined tissues. 


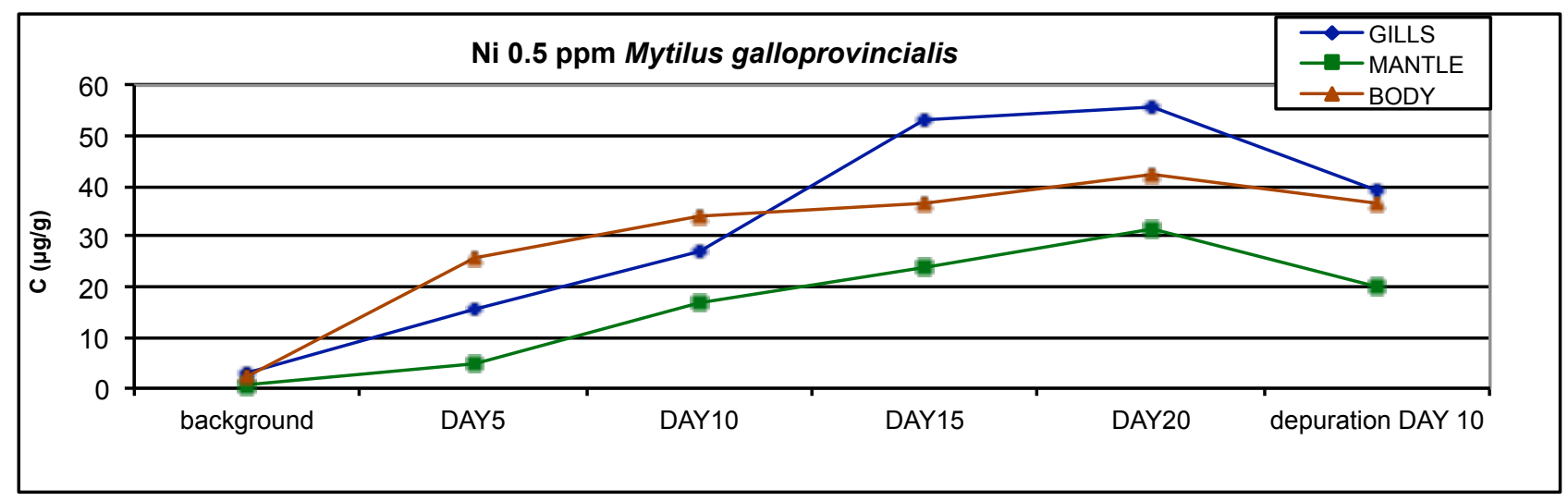

Fig. 1. Nickel content in gills, mantle and the remaining body from mussels (top) and soft clams (bottom) exposed to 0.5 ppm Ni for 5, 10, 15 and 20 days, and a final depuration period of 10 days.
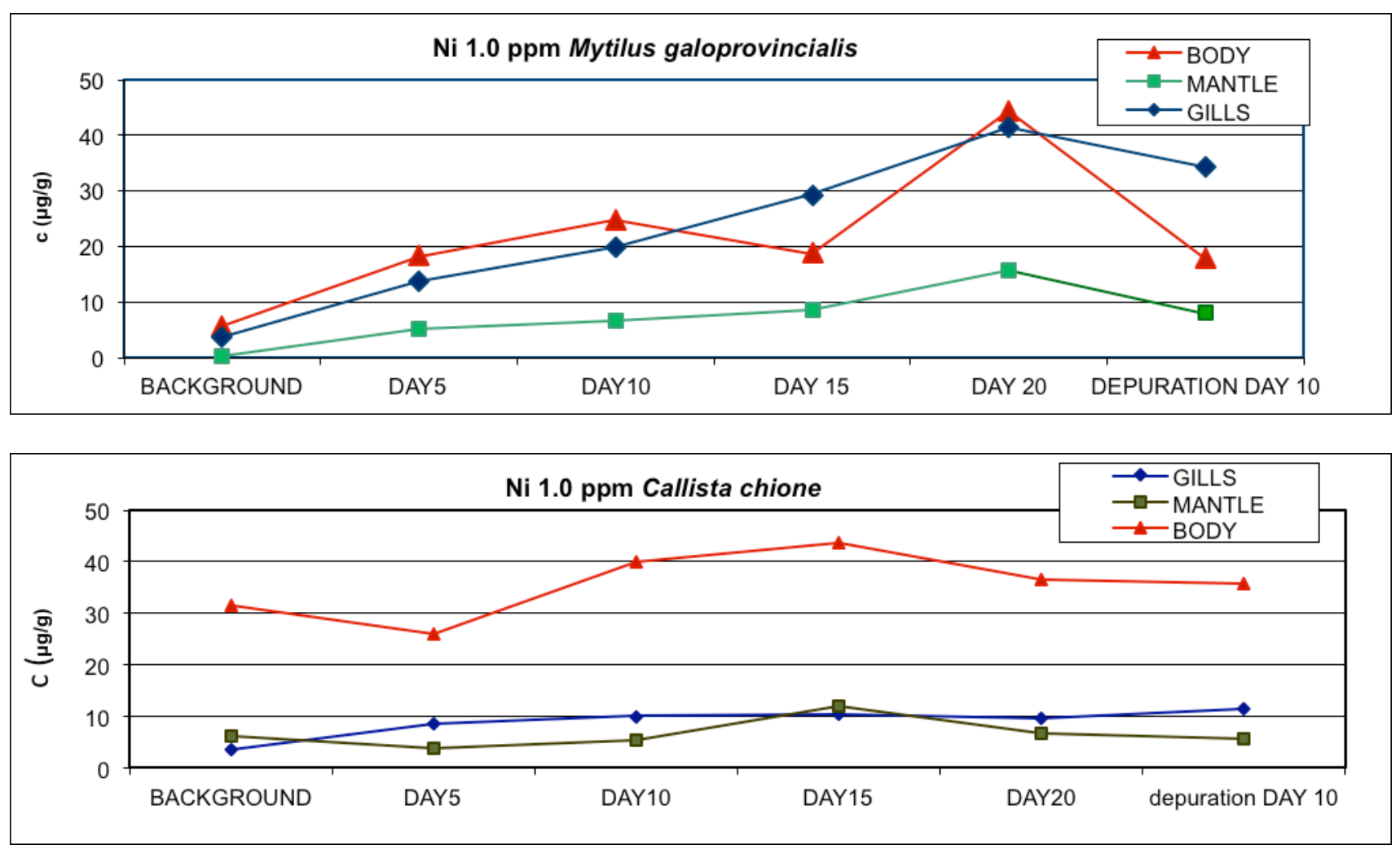

Fig. 2. Nickel content in gills, mantle and the remaining body from mussels (top) and soft clams (bottom) exposed to 1.0 ppm Ni for 5, 10, 15 and 20 days, and a final depuration period of 10 days.

Another important difference between the two bivalve organisms was observed when they were exposed to high Ni concentrations $(20 \mathrm{ppm})$. The mortality of mussels increased dramatically, and within a few days all the animals died. Surprisingly, all the soft clams exposed to $20 \mathrm{ppm} \mathrm{Ni}$ survived for the 20 days period of the experiment. Analysis of the tissues of these animals showed high $\mathrm{Ni}$ accumulation, which was decreased considerably after ten days of depuration (data not shown). This result shows that Callista chione exhibits a much higher tolerance to $\mathrm{Ni}$ contamination compared to Mytilus galloprovincialis. This result is consistent to the data obtained from lower Ni concentrations, and work is in progress to clarify the biochemical origins for this different behavior.

Possibly, a much more effective defensive system, capable to prevent heavy metals (at least $\mathrm{Ni}$ ), from accumulation, is present in Callista chione. At very high $\mathrm{Ni}$ contamination, the metal accumulates in the clams, however their defensive system is still able to keep them alive, in contrast to Mytilus galloprovincialis.

\section{Conclusions}

Two bivalves (the mussel Mytilus galloprovincialis and the soft clam Callista chione) were studied for their 

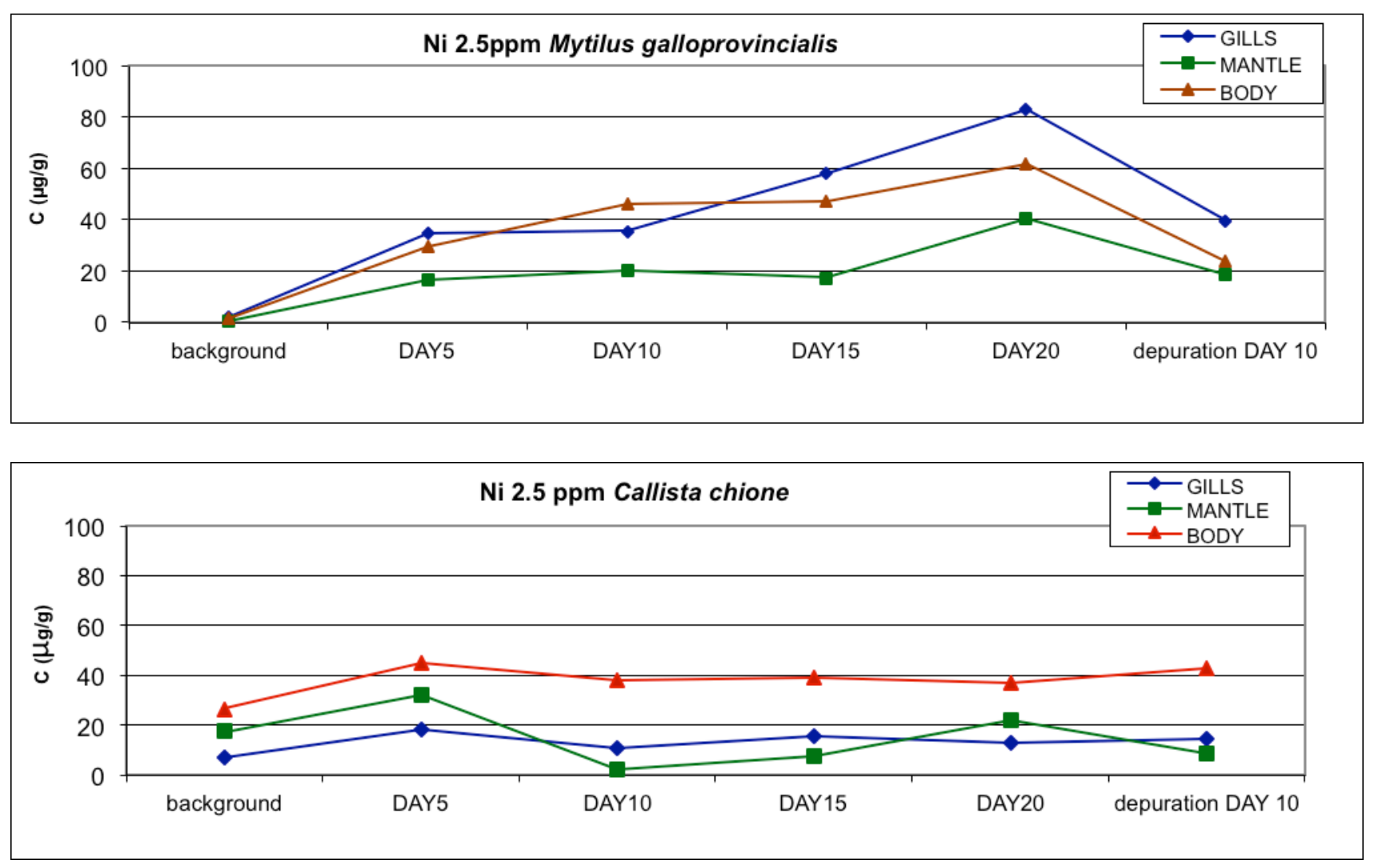

Fig. 3. Nickel content in gills, mantle and the remaining body from mussels (top) and soft clams (bottom) exposed to 2.5 ppm Ni for 5, 10, 15 and 20 days, and a final depuration period of 10 days.

behavior in a Ni contaminated environment. Gills and mantles were isolated from the bodies and the three resulting samples were examined for their $\mathrm{Ni}$ content after exposure for certain time periods to Nicontaminated seawater at various concentrations.

The two animals responded very differently to nickel contamination. More specifically, Mytilus galloprovincialis exhibited a continuously increasing accumulation of nickel with time, in all three tissues examined, whereas, Callista chione tissues did not accumulate considerable amounts of nickel. Exposure of the animals to higher $\mathrm{Ni}$ contamination (20 ppm $\mathrm{Ni}$ in seawater), revealed the different tolerance of the two species to this heavy metal, with Mytilus galloprovincialis being much more sensitive (all animals exposed to $20 \mathrm{ppm} \mathrm{Ni}$ died after a few days) compared to Callista chione (zero mortality during the 20 days of the experiment despite the accumulation of $\mathrm{Ni}$ in the tissues). It is possible that a much more effective defensive system exists in Callista chione compared to Mytilus galloprovincialis, which is able not only to prevent $\mathrm{Ni}$ (and possibly other metals) accumulation, but also to keep the animals alive at very high concentrations of this pollutant.

\section{Acknowledgements}

This research has been co-financed by the European Union (European Social Fund - ESF) and Greek national funds through the Operational Program "Education and Lifelong Learning" of the National Strategic Reference Framework (NSRF) - Research Funding Program: Heracleitus II. Investing in knowledge society through the European Social Fund.

\section{References}

Nesto N, Romano S, Moscino V, Mauri M, and DaRos L. Bioaccumulation and biomarker responses of trace metals and micro-organic pollutants in mussels and fish from the lagoon of Venice, Italy. Marine Pollution Bulletin 2007; 55: 469-484.

Nordberg GF, Fowler BA, Nordberg M, and Friberg LT (eds) in Handbook on the Toxicology of Metals $3^{\text {rd }}$ edition, 2007; Elsevier, pp. 84.

Zhou QF, Zhang JB, Fu JJ, Shi JB, Jiang GB. Biomonitoring: An appealing tool for assessment of metal pollution in the aquatic ecosystem. Analytica Chimica Acta 2008; 606: 135-150. 